\title{
Identification of Mutation in Exon2 of the NKX2.5 Gene in Bangladeshi Pediatric Patients with Congenital Hypothyroidism
}

\author{
Marjia Khatun, Sagana Shahreen Chowdhury, Toufiq Hasan Khan, Laila Anjuman Banu
}

\section{ABSTRACT}

Context and rationale: Congenital hypothyroidism is a prevalent endocrine disease that may occur due to the alteration in the sequence of nucleotides of the NKX2.5 gene. Though congenital hypothyroidism is quite common among the Bangladeshi pediatric population, there are few studies on the genetic basis of this disease.

Objective: This study aimed to identify any mutation in the exon2 of the NKX2.5 gene in Bangladeshi pediatric patients with congenital hypothyroidism.

Methods: Forty (40) Bangladeshi pediatric patients with congenital hypothyroidism were recruited, the sociodemographic data were collected and analyzed, DNA was isolated, quantity and quality of DNA were checked, polymerase chain reaction (PCR) was done, the amplicons were visually validated by gel electrophoresis and cycle sequencing was done by Sanger sequencing. The raw chromatogram data were analyzed and compared with the NCBI database by BLAST (Basic Local Alignment Search Tool) search.

Results: Sanger sequencing revealed two types of alteration in the nucleotide sequence. Nine patients showed substitutions (c.1051G $>$ T) and eight patients showed deletions (c.1143 delT-), and both substitution and deletion were present in four patients. This substitution and deletion occurred in the Sequence Tagged Site (STS) of the exon2 of the NKX2.5 gene and these are new variants and not reported in NCBI database.

Conclusion: In the present study, two types of variants were identified. So, further study to find out mutational status among Bangladeshi children might be helpful in enriching the database of mutational spectra of pediatric patients with congenital hypothyroidism.

Keywords: Congenital Hypothyroidism, Deletion, NKX2.5 gene, Sequence Tagged Site (STS), Substitution.

\section{INTRODUCTION}

Congenital hypothyroidism is one of the most frequent endocrine disorders in newborns with an incidence of about 1 in 3000 to 4000 live births in iodine-sufficient regions [1]. Congenital hypothyroidism is characterized by elevated levels of Thyroid Stimulating Hormone (TSH) in response to reduced levels of thyroid hormone. Patients with congenital hypothyroidism can be divided into two groups. One group has inborn errors of thyroid hormone biosynthesis (dyshormonogenesis) which are usually associated with enlarged gland and accounts for about $15 \%$ of cases. Another group has thyroid developmental defect (dysembryogenesis and dysgenesis) which accounts for $85 \%$ of the cases [2]. Congenital hypothyroidism with dyshormonogenesis and goiter is caused by the mutations in one of the genes coding for the protein responsible for thyroid hormone synthesis. Congenital hypothyroidism with
Published Online: September 30, 2020

ISSN: $2593-8339$

DOI: $10.24018 /$ ejmed.2020.2.5.487

\section{Marjia Khatun}

Department of Anatomy, Bangabandhu Sheikh Mujib Medical University, Bangladesh.

Sagana Shahreen Chowdhury

Department of Anatomy, Bangabandhu Sheikh Mujib Medical University, Bangladesh

Toufiq Hasan Khan

Department of Anatomy, Bangabandhu Sheikh Mujib Medical University, Bangladesh.

Laila Anjuman Banu*

Department of Anatomy, Bangabandhu

Sheikh Mujib Medical University,

Bangladesh.

(e-mail: dr.lailabanu@gmail.com)

*Corresponding Author dysembryogenesis and dysgenesis occurs due to disturbance in the gland organogenesis [3]. It may cause athyreosis, hypoplasia or ectopic thyroid. The normal development of the thyroid gland occurs during the early period of organogenesis. The thyroid anlage appears on the 20 to 22th day of gestation. Then thyroid bud migration begins on the $24^{\text {th }}$ day of gestation [4]. Following the growth process, the cells of the thyroid gland and the ultimo-branchial body migrate from the irrespective sites of origin and ultimately merge in the definitive thyroid gland. It arises from two distinct embryonic lineages: follicular cells and parafollicular cells. The follicular cells arise from the floor of the foregut of endodermal origin (median primordium) and produce thyroxine [4]. The parafollicular cells arise from the ultimo-branchial body of neural crest cell origin (lateral primordium) and produce calcitonin [1]. Many data suggest that, the development of embryonic thyroid glands and its migration occurs due to the interactions between 
several transcription factors. Four of these transcription factors are paired domain factor: paired box gene 8 (PAX8), Thyroid transcription factor 1 (TTF1 NKX2.1), forkhead box E1 (FOXE1) and thyroid transcription factor 2 (NKX2.5) [5]. They play a key role in the differentiation and growth of normal thyroid anlage and are required for normal thyroid development. Among these transcription factors, the $N K X 2.5$ is one of the most important transcription factors.

The NKX2.5 is a homeobox-containing transcription factor that is essential for both heart and thyroid morphogenesis [6]. It is present in both regions in the early period of gestation, but in the later period of gestation, it is confined to the thyroid primordium area. Molecular location of these gene is in the base pairs from 173,232,109 to $173,235,321$ on chromosome five. This gene has $10209 \mathrm{bps}$ linear DNA with two exons and three introns. Among them, exon 2 and exon-intron boundaries of exon 2 are the most common mutation sites [7]. Other names of this gene are: CHNG5, CSX, CSX1, HLHS2, NKX2E, NKX4-1, and VSD3. This transcription factor gene controls both heart and thyroid development in the early period of organogenesis. Mutation has been described not only in patients with heart disease but also in patients with thyroid ectopia/hypoplasia/athyreosis without a heart defect. In the later period of organogenesis, $N K X 2.5$ transcription factor is restricted to the thyroid primordium area, genetic alteration of the $N K X 2.5$ transcription factor gene, plays a key role in the patients with congenital hypothyroidism [8]. In $N K X 2.5$ gene from 7776 bps to $7977 \mathrm{bps}$ has Sequence Tag Site (STS) whose location and base sequence are known that could serve as marker for genetic and physical mapping of the gene [9].

\section{METHODS}

The study was a cross-sectional descriptive study and carried out from March 2019 to February 2020 in the Genomic Research Laboratory, Department of Anatomy, Bangabandhu Sheikh Mujib Medical University (BSMMU), Dhaka after getting formal approval from Institutional Review Board (IRB).

Forty (40) Bangladeshi pediatric patients with congenital hypothyroidism were recruited from the Department of Pediatric Endocrinology, BSMMU and Department of Pediatrics of Dhaka Medical College Hospital (DMCH) after being diagnosed by an expert pediatric endocrinologist. The sociodemographic data were collected and analyzed.

\section{A. DNA Isolation}

Genomic DNA was extracted from the blood sample that were taken from the patients by using commercial DNA extraction kit ReliaPrep ${ }^{\mathrm{TM}}$ (Promega, USA) as per manufacturer's instructions. Within the microcentrifuge tube, about $200 \mu \mathrm{l}$ blood was mixed with proteinase $\mathrm{K}$ and cell lysis buffer. Binding buffer, wash buffer and elution buffer were used sequentially for yielding the extracted DNA. According to the SOP (Standard Operating Procedure) the required amount of the reagents was taken for the DNA extraction procedure from the blood. The quantity and quality of the extracted DNA were measured and checked by NanoDrop spectrophotometer.

\section{B. Amplification}

Using Primer 3 plus software, forward and reverse primers were designed for the amplification of the targeted region of exon2 of $N K X 2.5$ gene (Table 1). The desired portion of $N K X 2.5$ gene was amplified by conventional PCR (polymerase chain reaction). Amplification of this sequence was accomplished by PCR. Amplification was performed on a Biometra thermal cycler (Biometra $\mathrm{GmbH}$, Germany). The amplicons were visually confirmed by $1 \%$ agarose gel electrophoresis (Fig. 1). PCR products were sent for Sanger sequencing.

TABLE 1: THE SEQUENCE OF FORWARD* (F) AND REVERSE* (R) PRIMERS AND THEIR RELEVANT INFORMATION'S THAT WERE USED IN THE PRESENT

\begin{tabular}{|c|c|c|c|c|c|}
\hline Primer & Sequence & $\begin{array}{c}\text { Primer } \\
\text { position }\end{array}$ & GC $\%$ & $\begin{array}{r}\mathrm{Tm} \\
\left({ }^{\circ} \mathrm{C}\right) \\
\end{array}$ & $\begin{array}{c}\text { Product } \\
\text { size }\end{array}$ \\
\hline $\mathrm{F}^{*}$ & $\begin{array}{c}\text { 5'- ACG AGG } \\
\text { ATC CCT TAC } \\
\text { CAT TAC TGT -3' }\end{array}$ & 7104 & $45.8 \%$ & $57.2^{\circ} \mathrm{C}$ & \multirow{2}{*}{938 bp } \\
\hline $\mathrm{R}^{*}$ & $\begin{array}{c}\text { 5'- ACT CAT TGC } \\
\text { ACG CTG CAT } \\
\text { AAT -3' }\end{array}$ & 7951 & $42.9 \%$ & $55.4^{\circ} \mathrm{C}$ & \\
\hline
\end{tabular}

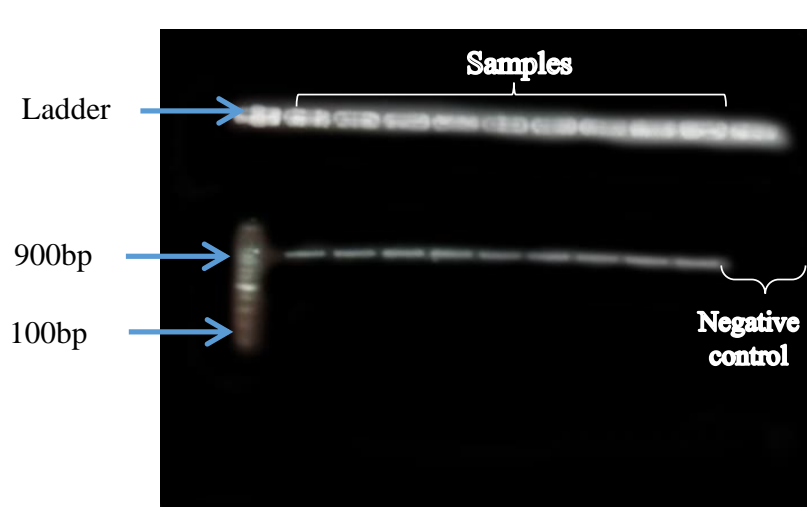

Fig. 1. Gel electrophoresis of the PCR products on $1 \%$ agarose gel. The desired product size (938bps) of the amplicons is shown in the specific bands compared with the standard $1 \mathrm{~Kb}$ DNA ladder in lane 1 .

\section{DNA sequencing}

For Sanger sequencing, the PCR products were run by using ABI-3500 Genetic Analyzer (Thermo Fisher Scientific, USA). BigDye ${ }^{\circledR}$ Terminator v3.1 Cycle Sequencing Kit were used for running the cycles.

\section{Data analysis}

Sanger sequencers generated a four-colored chromatogram which represented the results of the sequencing run. For the present research, data obtained from the Sanger sequencer in both $\mathrm{ABI}$ and SCF files were analyzed by using the Chromas ${ }^{\circledR}$ software. The sequences were compared with the NCBI (National Centre for Biotechnology Information) database by BLAST search.

\section{E. In Silico analysis of the effect of the mutations}

As locations of found variations in the present study were in the 3'UTR of the exon2 of the NKX2.5 gene. Human splicing finder

(HSF) 
[http://www.umd.be/HSF3/HSF.shtml] tool was used to predict the effect of these mutations in the splice sites [10]. Target Scan Human [http://www.targetscan.org/vert_72/] and PolymiRTS database [http://compbio.uthsc.edu/miRSNP/] were employed to identify the effect of these mutations on the miRNA target sites $[11,12]$. Target Scan Human identifies the target sites in the UTR regions while PolymiRTS predicts whether a point mutation or INDELS in $3^{\prime} \mathrm{UTR}$ affect the miRNA target site or not. Additionally, miRmap [https://mirmap.ezlab.org/] was used to analyze the interaction between the miRNA and their target sites [13].

\section{F. Ethical implication}

In the present research, all the pediatric patients with congenital hypothyroidism were treated equally and with due respect. The aim and possible benefits of the study was explained to the guardian and the caregiver of the pediatric patients with congenital hypothyroidism who had been participated in the research. Verbal and written consents were obtained from all the patients' guardian/caregiver of the pediatric patients. Each patient was given a special ID number for safeguarding confidentiality and protecting anonymity. All selected patients' guardian/caregiver were informed that the DNA samples of the pediatric patients with congenital hypothyroidism were used for research purpose only. They also were informed that they had the right to refuse to participate in or withdraw their patient's names from the research at any time.

\section{RESULTS}

Sanger sequencing revealed two types of alterations in the nucleotide sequence (Fig. 2). Nine patients showed substitutions (c.1051G>T) and eight patients showed deletions (c.1143 delT-) and both substitution and deletion were present in four patients. This substitution and deletion occurred in the Sequence Tagged Site (STS) of exon2 of the NKX2.5 gene and these are new variants and not reported in NCBI database. ID CH32 were used as a control sequence after $100 \%$ matching with the reference sequence of NKX2.5 gene by BLAST search. HSF tools predicted that the substitution of $\mathrm{G}$ to $\mathrm{T}$ at the position of 702 occurred in the late exonic position and could cause the activation of an exonic cryptic donor site which might cause the alteration of splicing. However, the deletions of one $\mathrm{T}$ at the position of 794 will not do any effect on splicing (Table 2).

Target Scan Human and PolymiRTS predicted that both variants affected the miRNA target site. The substitution created a new target site for hsa-miR-4286 (Fig. 3). On the other hand, deletion of one $\mathrm{T}$ at the position of 794 disrupted the target site of hsa-mir-495-3p leading to no binding of miRNA (Fig. 4).
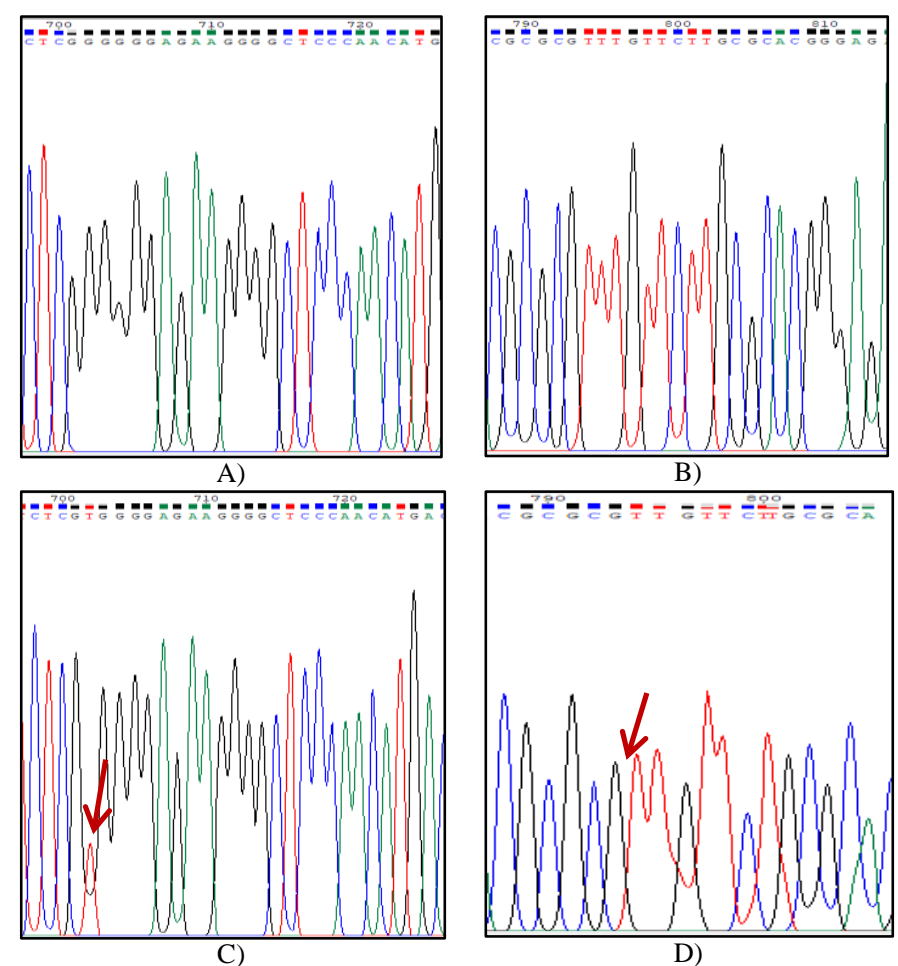

Fig. 2. Sample ID CH32 was used as the control sequence $(\mathrm{A}, \mathrm{B})$ for comparing with the mutant sequence. In sample ID CH33, ' $\mathrm{G}$ ' has been substituted by ' $\mathrm{T}$ ' (c.1051 G>T) at nucleotide position 1051bps[C]. In sample ID CH2, 'T' has been deleted (c.1143Tdel -) at nucleotide position 1143 bps [D].

TABLE 2: THE OUTPUT OF HSF TOOLS WHICH SHOWS RELEVANT RESULTS

\begin{tabular}{|c|c|c|c|}
\hline Mutation & $\begin{array}{c}\text { Predicted } \\
\text { Signal }\end{array}$ & Position & Interpretation \\
\hline $\begin{array}{c}\text { Substitution } \\
\text { of } G \text { to } T\end{array}$ & $\begin{array}{c}\text { New Donor } \\
\text { Site }\end{array}$ & $\begin{array}{c}\text { Normal: A C T C G } \\
\text { GGGGG A G A } \\
\text { Mutant: A C T C G T G } \\
\text { GGG A G A }\end{array}$ & $\begin{array}{l}\text { Activation of } \\
\text { exonic cryptic } \\
\text { donor site. } \\
\text { Potential } \\
\text { alteration of } \\
\text { splicing }\end{array}$ \\
\hline $\begin{array}{c}\text { Deletion of } \\
\text { one } T\end{array}$ & $\begin{array}{c}\text { ESS* site } \\
\text { broken }\end{array}$ & $\begin{array}{c}\text { Normal: C G C G T TT } \\
\text { G T T C T T G } \\
\text { Mutant: C G C G - T T } \\
\text { G T T C T T G }\end{array}$ & $\begin{array}{c}\text { Alteration of ESS } \\
\text { Site. } \\
\text { Probably no } \\
\text { impact on splicing }\end{array}$ \\
\hline
\end{tabular}

*ESS- Exonic splicing silencer.

\section{DISCUSSION}

In the present study, forty pediatric patients with congenital hypothyroidism were selected for identification of mutation in the exon2 of the $N K X 2.5$ gene. The $N K X 2.5$ gene has two exons, one coding sequence and one Sequence Tagged Site (STS) area. Among these two exons, the exon2, $1100 \mathrm{bps}$ nucleotides in length, extends from 7104 to 8204 bps and also contains STS [7].

In the present study, the primer was designed covering the whole region of exon2 of the $N K X 2.5$ gene. Upon Sanger sequencing and chromatogram interpretation, two types of changes were identified. These changes occurred in the STS area. STS sequences have a single occurrence in the genome and whose location and base sequence are known and can be uniquely amplified by the polymerase chain reaction (PCR) using a pair of primers. 


\begin{tabular}{|c|c|}
\hline Normal & Mutant \\
\hline 707 & 707 \\
\hline $5^{\prime}(\mathrm{mRNA})$ & $5^{\prime}$ (mRNA) । \\
\hline АACAGCTCCCTGACTCTCGGGGGGAGAAGGGGC & $\begin{array}{l}\text { AACAGCTCCCTGACTCTCGTGGGGAGAAGGGGC } \\
\text { |||||| }\end{array}$ \\
\hline CCAUGGUCCUCACCCCA & CCAUGGUCCUCACCCCA \\
\hline \multirow[t]{2}{*}{ (hsa-mir-4286) } & $\Delta \mathrm{G}$ duplex \\
\hline & $\Delta \mathrm{G}$ binding \\
\hline \multirow[t]{3}{*}{ No Binding } & $\Delta \mathrm{G}$ duplex seed -10.10 \\
\hline & $\Delta \mathrm{G}$ binding seed -10.15 \\
\hline & $\Delta \mathrm{G}$ binding seed -10.15 \\
\hline
\end{tabular}

Fig. 3.The substitution of $\mathrm{G}$ to $\mathrm{T}$ at the position of 702 creates a new binding site for hsa-mir-4286. But normally, without substitution the sequence has no identifying site for hsa-mir-4286.

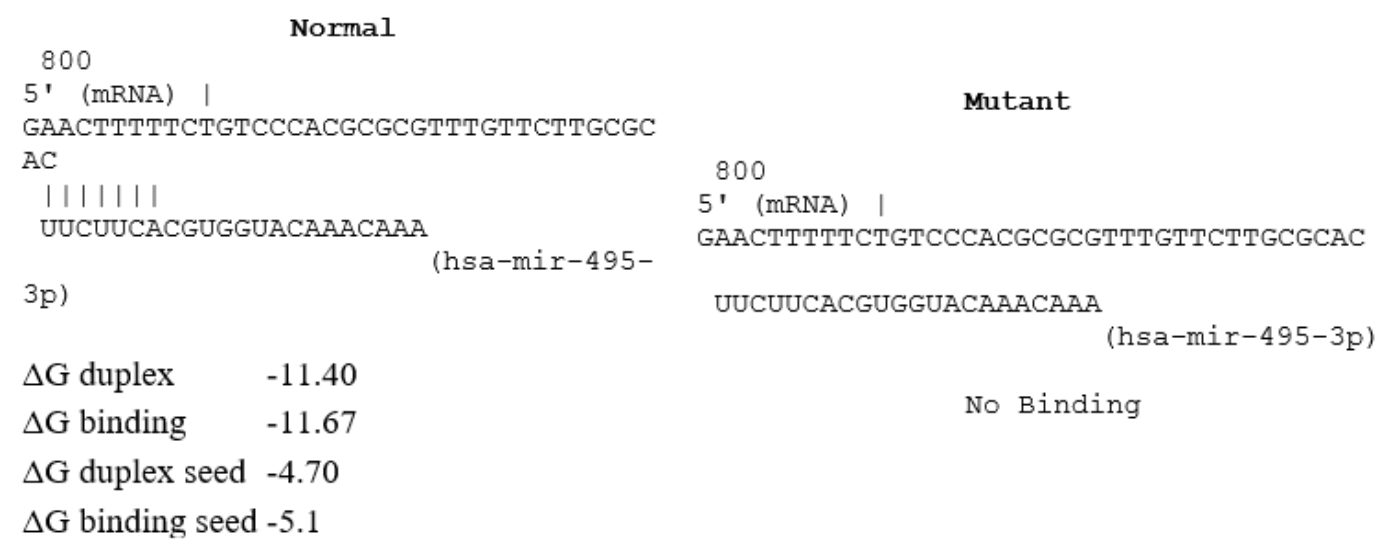

Fig. 4 Deletion of one $\mathrm{T}$ at the position of 794 disrupts the target site (at $800 \mathrm{bps}$ ) of hsa-mir-495-3p leading to no binding of miRNA. Bur normally, without deletion, the sequence has the binding site for hsa-mir-495-3p.

Among the two changes, nine patients showed substitutions at $1051 \mathrm{bp}(\mathrm{c} .1051 \mathrm{G}>\mathrm{T} \mathrm{bp})$. As this substitution does not involve in amino acid alteration and as it is present in the STS area, it may be used as a probe, and in chromosome mapping [9].

In eight pediatric patients with congenital hypothyroidism, $\mathrm{T}$ is deleted in the $1143 \mathrm{bps}$ of the query sequence (c.1143 delT) in comparison with the standard sequence of the gene by BLAST search. This deletion occured in the exonic region and in the STS area of exon2 of the NKX2.5 gene. Four patients with congenital hypothyroidism showed both deletion and substitution in 1143bps and 1051 bps. The gene sequence was checked for pathogenicity with the reference sequence (RefSeq), Clinical variation (clinvar), malacards and Human Genome Variation Society (HGVS). But this type of change has not been yet reported and recorded. So, further study regarding the effect of these new variants can be done.

Several studies have been conducted focusing on the NKX2.5 gene. In a study performed by Dentice et al., it was reported that mutational screening was done covering the entire NKX2.5 coding sequence on 241 patients. They observed three mutations (R25C, A119S and R161P) in four patients with thyroid dysgenesis (three patients with thyroid ectopy and one with athyreosis) [14]. They recommended that the NKX2.5 gene was involved in the pathogenesis of congenital hypothyroidism with ectopy or athyreosis of the thyroid gland. It is noticeable that Dentice et al. found mutations in only four patients out of 241 patients, but in the present study, the nucleotide changes are present among 21 patients out of 40 patients. The striking finding is that all the identified changes in the present study are located in the STS site of exon 2 of the $N K X 2.5$ gene.

Brust et al. conducted a study on twenty-seven patients with primary congenital hypothyroidism aged 3 to 19 years [15]. All the patients presented with high TSH levels after 4 weeks of levothyroxine suspension. They observed synonymous variation (SNP rs2277923) within the $N K X 2.5$ gene in the study population that did not change the amino acid. Cerqueira et al. studied with thyroid dysgenesis patients and found polymorphism (c.63A>G) among the study population. This variation did not involve an amino acid alteration [16].

Similarity has been observed by Khatami et al. regarding mutation detection of both exons of the NKX2.5 gene, and found two polymorphisms among the study population. A C$\mathrm{T}$ heterozygous missense mutation $(\mathrm{c} .73 \mathrm{C}>\mathrm{T}$ ) and $\mathrm{A}-\mathrm{G}$ transition $(\mathrm{c} .63 \mathrm{~A}>\mathrm{G})$ in exon1 of the gene had been noted among the study population. One resulted in the substitution of the arginine residue by a cysteine residue at position 25 (R25C). Other did not alter the glutamic acid residue (E21E). This polymorphism was detected in $31(47.6 \%)$ of the patients and in $16(25.8 \%)$ of the healthy controls of the same ethnic 
background. Both of these mutations $(73 \mathrm{C}>\mathrm{T}$ and $63 \mathrm{~A}>\mathrm{G})$ were previously described in patients with thyroid dysgenesis and congenital heart defects. No change was found in the exon2 of this gene [8].

From the above discussion many studies are found regarding the genetic basis of the $N K X 2.5$ gene. No mutation but polymorphism was found on the study population. But the above-mentioned study did not found any mutation or polymorphism in the STS region of the exon2 of the NKX2.5 gene.

In the present study, there was no control group and the sample size was small. The detected variation is not yet reported in the NCBI database. As the STS is an important marker and the changes are new, so further research should be done including this region.

To our knowledge, the present study was the first to determine the $N K X 2.5$ gene mutation in Bangladeshi pediatric patients with congenital hypothyroidism. In the present study, the changes were found among 21 study patients. This might be quite high regarding nucleotide change. It may be due to geographic variation.

The findings of nucleotide changes in the present study might be due to several reasons. So, the findings need to be analyzed up to the protein level detection. This approach of genetic study for the detection of mutation in the NKX2.5 gene in the pediatric patient with congenital hypothyroidism will pave a great opportunity for the clinicians for diagnostic, prognostic and therapeutic indices.

\section{CONCLUSION}

In the present study, two types of variations were identified in twenty-one patients which were new variants and all occurred in the STS site of the gene. The results of the present study may help to detect the frequency of mutation of the NKX2.5 gene in the occurrence of the disease. So, further study to find out mutational status among Bangladeshi children might be helpful in enriching the database of mutational spectra of pediatric patients with congenital hypothyroidism.

\section{ACKNOWLEDGEMENTS}

We would like to acknowledge the authority of BSMMU for funding support of this study. We thank the Department of Anatomy, BSMMU for providing the infrastructure and other research facilities. We also acknowledge Department of Pediatrics, Bangabandhu Sheikh Mujib Medical University (BSMMU) and Department of Pediatrics, Dhaka Medical College Hospital for giving permission for sample and data collection.

\section{REFERENCES}

[1] Montanelli L \& Tonacchera M, "Genetics and phenomics of hypothyroidism and thyroid dys- and agenesis due to PAX8 and TTF1 mutations,"Molecular \& Cellular Endocrinology. 322. 64-71, 2010.

[2] Hermanns, P, Grasberger, H, Refetoff, S \&Pohlenz, J, “ Mutation in the $N K X 2.5$ gene and the PAX8 promoter in a girl with thyroid dysgenesis,"J ClinEndocrinolMetabol. 96, 6, E977-E981, 2011.

[3] Ramos, HE, Nesi-Franca, S, Boldarine, VT, Pereira, RM \&Chiamolera, MI, Camachoo, CP, Graf, H, de Lacerda, L, Carvalho, GA \&Maciel, RMB, "Clinical and molecular analysis of thyroid hypoplasia: A population-based approach in southern Brazil," Thyroid. 19, 61-68, 2009.

[4] Sadler, T.W 2016, Langman's Medical Embryology, 13th edn, Library of Congress Cataloging-in publication Data, South Carolina.

[5] Narumi, S, Muroya, K, Asakura, Y, Adachi, M \& Hasegawa, T, "Transcription factor mutations and congenital hypothyroidism: Systematic genetic screening of a population-based cohort of Japanese patients,"J ClinEndocrinolMetabol. 95, 1981-1985,2010.

[6] van Engelen, K, Mommersteeg, MTM, Baars, MJH, Lam, J, Ilgun, A, van Trotsenburg, ASP, Smets AMJB, Christoffels, VM, Mulder, BJM \&Postma, AV, "The ambiguous role of NKX2-5 mutations in thyroid dysgenesis," PLOS One. 7, 12, 2012.

[7] National Center for Biotechnology Information (NCBI) 2017, Homo sapiens Annotation release 109, RefSeqGene on chromosome 5 GRCh38.

[8] Khatami M, Heidari MM, Tabesh F, Ordooei M \&Salehifar Z "Mutation analysis of $N K X 2.5$ gene in Iranian pediatric patients with congenital hypothyroidism,"J PediatrEndocrinolMetabol.10, 1-6,2017.

[9] Green, ED \& Green, P, "Sequence tagged site content mapping of human chromosome: Theoretical consideration and early experience,"Genome Research. 1, 77-90,(1991).

[10] Desmet, F. O. et al., "Human Splicing Finder: an online bioinformatics tool to predict splicing signals," Nucleic Acid Res. 37, e67, 2009.

[11] Agarwal V, Bell GW, Nam J, Bartel DP,"Predicting effective microRNA target sites in mammalian mRNAs,"eLife, 4:e05005, 2015.

[12] Pickrell, J. K. et al.,"Understanding mechanisms underlying human gene expression variation with RNA sequencing," Nature. 464, 768772,2010 .

[13] Vejnar, C. E., \&Zdobnov, E. M, "MiRmap: comprehensive prediction of microRNA target repression strength,"Nucleic acids research, 40(22), 11673-11683, 2012.

[14] Dentice M, Cordeddu V, Rosica A, Ferrara AM, Santarpia L, Salvatore D, Chiovato L, Perri A, Moschini L, Fazzini C, Olivieri A, Costa P, Stoppioni V, Baserga M, De Felice M, Sorcini M, Fenzi G, Di Lauro R, Tartaglia M \&Macchia PE,"Missence mutation in the transcription factor $N K X 2.5$ : A novel molecular event in the pathogenesis of thyroid dysgenesis," JClinEndocrinolMetabol. 91, 4, 1428-1433, 2006.

[15] Brust ES, Beltrao CB, Chammas MC, Watanabe T, Sapienza MT\& Marui S,"Absence of mutations in PAX8, NKX2.5 and TSH receptor genes in patients with thyroid dysgenesis,"Arch BrazEndocrinolMetab,56, 173-177, 2012.

[16] Cerqueira TL, Ramos Y, Strappa G, Martin DS, Jesus M, Gonzaga J, Ferreira P, Costa A, Fernandes V, Amorim T, Ladeia MA \& Ramos $\mathrm{H}$,"The c.63A $>\mathrm{G}$ polymorphism in the $N K X 2.5$ gene is associated with thyroid hypoplasia in children with thyroid dysgenesis,"Arch EndocrinolMetab, 59, 562-567, 2015. 


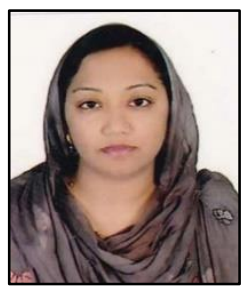

Dr. Marjia Khatun completed her post-graduation (MS) in anatomy in 2020 from Bangabandhu Sheikh Mujib Medical University, Dhaka, Bangladesh. Currently she is a lecturer of the Department of Anatomy at Khulna Medical College, Khulna; Bangladesh. During the period of her post-graduation at Bangabandhu Sheikh Mujib Medical University, Dr. Marjia conducted her research on genetic basis of congenital hypothyroidism in the pediatric patients. Her main research interest includes molecular and genetic basis of medical disorders. Dr. Marjia has publications in refereed journals on the topic of BRCA1 mutation in the breast cancer patients as a coauthor.

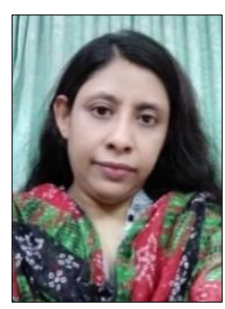

Dr. Sagana Shahreen Chowdhury completed her post-graduation (MS) in anatomy in 2020 from Bangabandhu Sheikh Mujib Medical University, Dhaka, Bangladesh. Currently she is a lecturer of anatomy at Shahid Suhrawardy Medical College, Dhaka, Bangladesh. During the period of her postgraduation at Bangabandhu Sheikh Mujib Medical University, dr. Sagana conducted her research on BRCA1 mutation in the breast cancer patients. Her main research interest includes molecular and genetic basis of medical disorders. Dr. Sagana has publications in refereed journals on the topic of BRCAl mutation in the breast cancer patients and on the topic of prevalence of HIV, hepatitis B and C virus in overseas job seekers of Bangladesh with the possible routes of transmission.

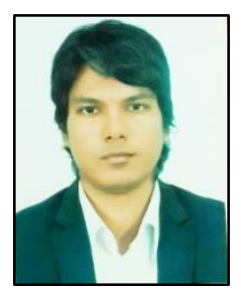

Dr. Toufiq Hasan Khan completed his postgraduation (MS) in anatomy in 2020 from Bangabandhu Sheikh Mujib Medical University, Dhaka, Bangladesh. Currently he is a lecturer of the Department of Anatomy at Sir Solimullah Medical College, Dhaka; Bangladesh. During the period of his post-graduation at Bangabandhu Sheikh Mujib Medical University, he conducted research on genetic basis of leukemia patients. Dr. Toufiq has publications in refereed journals on the topic of BRCAl mutation in the breast cancer patients as a co-author.

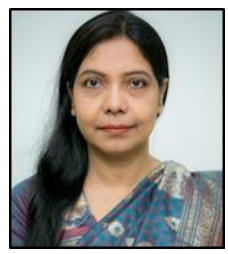

Prof. Dr. Laila Anjuman Banu is a career medical professional and teacher. She is now working as Prof. Genetics and Molecular Biology in the Department of Anatomy at Bangabandhu Sheikh Mujib Medical University (BSMMU). She passed 9th Bangladesh Civil Service (BCS Health Cadre), earlier, and entered into Ministry of Health and Family Welfare. During her professional carrier she worked at several renowned medical Institute like Dhaka Medical College and Sir Salimullah medical college. She also served as the Chairman, Department of Anatomy of BSMMU from 2015 to 2018. In addition to his current responsibility, she also established a Genome Research Laboratory at BSMMU under Higher Education Quality Enhancement project (HEQEP) funded by World Bank and GOV of Bangladesh.

She has a MS degree in molecular Biology, as well as Master of Medical Education (MMEd), Master of Philosophy (MPhil) and Bachelor MBBS Degree. She is adjunct faculty of Bangladesh College of Physicians and Surgeons (BCPS) and Bangladesh Medical Research Council (BMRC). She organized and represented numerous international meetings and international conferences related to medical professional. she is trained in latest molecular technology from as Academic Medical Center, University Amsterdam, Netherlands, UK, Singapore, Thailand, Malaysia and India.

She participated in a number of Global Good Ethical and Legal Issues of human genomics n Programmer as Senior lead researchers. She has extensive research knowledge in the human genome research and post graduate medical curriculum development in Ministry of Health and Family Welfare and Ministry of Education of Bangladesh.

She has more than sixty indexed articles in International Journal and she is acting as reviewer and editor of number of International Journal. She published number of book chapters in Jaypee Medical Publishers of India. She also supervises number of these researches of BSMMU. 